\title{
Chapter 1 \\ European Didactic Traditions \\ in Mathematics: Introduction and Overview
}

\author{
Werner Blum, Michèle Artigue, Maria Alessandra Mariotti, Rudolf Sträßer \\ and Marja Van den Heuvel-Panhuizen
}

\begin{abstract}
European traditions in the didactics of mathematics share some common features such as a strong connection with mathematics and mathematicians, the key role of theory, the key role of design activities for learning and teaching environments, and a firm basis in empirical research. In this first chapter, these features are elaborated by referring to four cases: France, the Netherlands, Italy and Germany. In addition, this chapter gives an overview on the other chapters of the book.
\end{abstract}

Keywords European didactic traditions $\cdot$ Overview

\subsection{Introduction}

Across Europe, there have been a variety of traditions in mathematics education, both in the practice of learning and teaching at school and in research and development, which have resulted from different cultural, historical and political backgrounds. Despite these varying backgrounds, most of these traditions share some common

\author{
W. Blum ( () \\ Department of Mathematics, University of Kassel, Kassel, Germany \\ e-mail: blum@mathematik.uni-kassel.de \\ M. Artigue \\ University Paris Diderot-Paris 7, Paris, France \\ M. A. Mariotti \\ Department of Information Engineering and Mathematics Science, \\ University of Siena, Siena, Italy \\ R. Sträßer \\ Institut für Didaktik der Mathematik, University of Giessen, Giessen, Germany \\ M. Van den Heuvel-Panhuizen \\ Utrecht University, Utrecht, The Netherlands \\ M. Van den Heuvel-Panhuizen \\ Nord University, Bodø, Norway \\ (C) The Author(s) 2019


features, one feature being the use in many languages of the word didactic (derived from the Greek didáskein, which means teaching) to denote the art and science of teaching and learning (didactiek in Dutch, didactique in French, didáctica in Spanish, didattica in Italian, didaktika in Czech, dydaktyka in Polish and didaktik( $k$ ) in Swedish, Danish, Norwegian and German) rather than education, which is preferred in Anglo-Saxon traditions. These European didactic traditions can be traced back as far as Comenius' Didactica Magna in the 17th century, the first comprehensive opus on aims, contents and methods of teaching. These traditions share in particular the following common features: a strong connection with mathematics and mathematicians, the key role of theory, the key role of design activities for learning and teaching environments, and a firm basis in empirical research. Other common features (such as the important role of proofs and proving or of linking mathematics with the real world) can be considered part of those four features.

In the following sections, we will elaborate a bit more on these four common features. ${ }^{1}$ They will be made more concrete by referring briefly to four selected cases of European traditions in the didactics of mathematics: France, the Netherlands, Italy and Germany. In the following four chapters (Chaps. 2-5) of this volume, these four traditions are presented in considerable detail. In particular, the role of the four key features in those traditions will become more transparent. The last two chapters are devoted to another two European traditions, the Scandinavian (Denmark, Norway and Sweden; Chap. 6) and the Czech/Slovak (Chap. 7). Although this chapter is written in English, we will speak, throughout the chapter, of the 'didactics of mathematics' instead of 'mathematics education' when we refer to the discipline dealing with all aspects of teaching and learning mathematics in the above-mentioned European traditions.

\subsection{The Role of Mathematics and Mathematicians}

Here we will highlight the role that some outstanding mathematicians have played in the didactics of mathematics in these four countries by their involvement in educational issues such as designing curricula for school and for teacher education and writing textbooks and by their fostering of the development of didactics of mathematics as a research field. In this respect, a prominent exemplar is Felix Klein (see Tobies, 1981), who also had a great influence on other mathematicians who had the opportunity of getting to know his work during their visits to Germany as researchers.

An important occasion for international comparison of different experiences in the didactics of mathematics was the Fourth International Congress of Mathematicians, which took place in Rome from 6 to 11 April 1908. During this congress, the International Commission on the Teaching of Mathematics (Commission Internationale de 1'Enseignement Mathématique, Internationale Mathematische Unterrichtskom-

\footnotetext{
${ }^{1}$ These sections refer to the corresponding sections in Blum, Artigue, Mariotti, Sträßer, and Van den Heuvel-Panhuizen (2017).
} 
mission and Commissione Internazionale dell'Insegnamento Matematico in France, Germany and Italy, respectively) was founded (details of the history of this institution can be retrieved at http://www.icmihistory.unito.it/timeline.php).

After the traumatic interruptions for the First and Second World Wars, mathematicians were again involved in various reform movements. In many countries, the ideas and principles of the so-called New Math were shared in the 1960s and 1970s. We can recognise a common interest in reforming curricula, which is certainly related to the impact a new generation of mathematicians had on the reorganisation of mathematics that was initiated by the Bourbaki Group. Thus, although the concrete results of the New Math movement were very different in various countries, a common feature was that substantial innovation entered into school practice through the active involvement of eminent figures such as Gustave Choquet, Jean Dieudonné and André Lichnerowicz in France; Emma Castelnuovo in Italy; and Hans Freudenthal in the Netherlands.

In the context of this reform, new perspectives developed, beginning in the late 1970 s, that moved the focus of reflection from issues concerning mathematical content and its organisation in an appropriate curriculum to issues concerning the description and explanation of the learning and teaching of mathematics, giving birth to a new scientific discipline, the didactics of mathematics, that rapidly developed through active international interaction. In some cases, for instance in France and Italy, it is possible to recognise again the strong influence of the mathematicians' community, since the first generation of researchers in the didactics of mathematics consisted in these countries for the most part of academics affiliated with mathematics departments. This observation does not ignore the existence of a recurrent tension between mathematicians and researchers in didactics of mathematics.

In summary, some common features that can be considered the core of the European tradition of didactics of mathematics can be directly related to the fruitful commitment of mathematicians to educational issues and their intent to improve the teaching and learning of mathematics. One example is the strong role that proofs and proving have in these European traditions. It can be said that in all four cases, mathematics has been and still is the most important related discipline for the didactics of mathematics, and there is still a lively dialogue between mathematicians and didacticians (researchers in the didactics of mathematics) on educational issues.

\subsection{The Role of Theory}

The word theory in the didactics of mathematics has a broad meaning, ranging from very local constructs to structured systems of concepts; some are 'home-grown' while others are 'borrowed' with some adaptation from other fields, and some have developed over decades while others have emerged only recently. This diversity can also be observed in the four European traditions under consideration.

The French tradition is certainly the most theoretical of these. It has three main pillars: Vergnaud's theory of conceptual fields (see Vergnaud, 1991), Brousseau's 
theory of didactical situations (TDS; see Brousseau, 1997) and the anthropological theory of the didactic (ATD) that emerged from Chevallard's theory of didactic transposition (see Chevallard \& Sensevy, 2014). These developed over decades with the conviction that the didactics of mathematics should be a scientific field of research with fundamental and applied dimensions supported by genuine theoretical constructions and appropriate methodologies, giving an essential role to the observation and analysis of didactic systems and to didactical engineering. These theories were first conceived as tools for the understanding of mathematics teaching and learning practices and processes, taking into consideration the diversity of the conditions and constraints that shape them, and for the identification of associated phenomena, such as the 'didactic contract'. The three theories are also characterised by a strong epistemological sensitivity. Over the years, this theoretical landscape has been continuously enriched by new constructions and approaches, but efforts have always been made to maintain its global coherence.

The Dutch tradition is less diversified, as it has developed around a single approach known today as Realistic Mathematics Education (RME; see Van den HeuvelPanhuizen \& Drijvers, 2014). It also emerged in the 1970s with Freudenthal's intention to give the didactics of mathematics a scientific basis. Similar to the French case, this construction was supported by a deep epistemological reflection: Freudenthal's didactical phenomenology of mathematical structures (see Freudenthal, 1983). In this tradition, theoretical development and design are highly interdependent. This is visible in the RME structure, which is made of six principles clearly connected to design: activity, reality, level, intertwinement, interactivity and guidance. Through design research in line with these principles, many local instruction theories focusing on specific mathematical topics have been produced. RME is still in conceptual development, benefiting from interactions with other approaches such as socioconstructivism, instrumentation theory and embodied cognition theory.

In the Italian tradition, it is not equally possible to identify major theories that would have similarly emerged and developed, despite a long-term tradition of action research collaboratively carried out by mathematicians interested in education and by teachers. Progressively, however, a specific research trend has emerged from this action research and consolidated within a paradigm of research for innovation, leading to the development of specific theoretical frames and constructs (for an overview, see Arzarello \& Bartolini Bussi, 1998). Boero's construct of field of experience, Bartolini Bussi and Mariotti's theory of semiotic mediation, and Arzarello's constructs of semiotic bundle and action, production and communication (APC) space represent this trend well.

In Germany, scholars since the early 1970s have aimed to create the field of didactics of mathematics as a scientific discipline, as shown by articles published in ZDM in 1974-75 (see Griesel, 1974; Winter, 1975; Wittmann, 1974) and the efforts made by Hans-Georg Steiner to establish an international debate on the theory of mathematics education and the underlying philosophies and epistemologies of mathematics within an international Theory of Mathematics Education (TME) group he founded in 1984. However, it would be difficult to identify a specific German way of approaching theoretical issues in the didactics of mathematics even though, 
seen from the outside, the interactionist approach initiated by Heinrich Bauersfeld, for example, seems to have been influential at an international level. Research in Germany currently uses a large variety of 'local' theories and corresponding research methods (for more information, see Jahnke et al., 2017).

Thus, the theoretical landscape offered by these four traditions is diverse and heterogeneous. Considering that such diversity is inherent to this field of research, the European community of research in the didactics of mathematics has developed specific efforts to build connections, an enterprise today known as 'networking between theories' (see Bikner-Ahsbahs \& Prediger, 2014). Not surprisingly, researchers from these four traditions are particularly active in this area.

\subsection{The Role of Design Activities for Teaching and Learning Environments}

Design activities in the didactics of mathematics can involve the design of tasks, lessons, teaching sequences, textbooks, curricula, assessments, and ICT-based material or programs for teacher education and can be done by teachers, educators, textbook authors, curriculum and assessment developers, ICT designers, and researchers. Such activities can be ad hoc or research based. Without design, no education is possible. It is through designed instructional material and processes, in which the intended what and how of teaching is operationalised, that learning environments for students can be created. As such, educational design forms a meeting point of theory and practice through which they influence each other reciprocally. All four European didactic traditions reflect this role of design.

In France, the design of mathematical tasks, situations and sequences of situations is essential to didactic research and is controlled by the theoretical frameworks underlying this research (see Sect. 1.3). This is clearly reflected in the methodology of didactical engineering within the theory of didactical situations that emerged in the early 1980s. Designs are grounded in epistemological analyses, and situations are sought that capture the epistemological essence of the mathematics to be learned. In the last decade, the anthropological theory of the didactic has developed its own design perspective that gives particular importance to identifying issues that question the world and have strong mathematical potential. Design as a development activity takes place mostly within the IREMs. Dissemination happens through the publications of these institutes, professional journals, curricular resources and some textbooks. Up to now, only a few research projects were aimed at upscaling.

In the Netherlands, a strong tradition in design can be found. Making things work, looking for pragmatic solutions, creativity and innovation are typical features of the Dutch culture. This emphasis on design can also be found in the didactics of mathematics. At the end of the 1960s, the reform of mathematics education started with designing an alternative for the mechanistic mathematics education that then prevailed. Initial design activities were practice oriented. The theory development that 
resulted in Realistic Mathematics Education (see Sect. 1.3) grew from this practical work and later guided further design activities. Design implementation, including contexts, didactical models, longitudinal teaching-learning trajectories, textbook series, examination programs, mathematics events, and digital tools and environments, has been realised through a strong infrastructure of conferences, journals and networks.

In Italy, the role of design has also changed over time. The period from the mid1960 s to the mid-1980s was characterized by a deep epistemological concern and a strong pragmatic interest in improving classroom mathematics teaching. Theoretical reflection on didactical suggestions and their effectiveness was not so strong. The focus was on the content and its well-crafted presentation in practice, based on conceptual analyses. The period from the mid-1980s to the present can be characterised by long and complex processes targeting the development of theoretical constructs based on teaching experiments, with the design of teaching and learning environments as both an objective and a means of the experimentation.

Within the German didactic tradition, two periods can be distinguished. Before the 1970s and 1980s, design activities were mostly meant for developing learning and teaching environments for direct use in mathematics instruction. These design activities belonged to the long German tradition of Stoffdidaktik, which focused strongly on mathematical content and course development, with less attention on course evaluation. In the 1970s, an empirical turn occurred, resulting in design activities done to study the effect of specified didactical variables through classroom experiments. Course development became less prominent, but this was-in one strand of German didactics of mathematics - counterbalanced by defining didactics of mathematics as a 'design science' with a strong focus on mathematics. Currently, both approaches to design activities can be found in Germany and have evolved into a topic-specific didactical design research connecting design and empirical research.

\subsection{The Role of Empirical Research}

As discussed in Sect. 1.4, designing learning environments for mathematics has been an important activity in all four countries. This created the need to legitimise such environments. One way to do this has been to show the effectiveness of these environments by means of empirical research (whatever 'effectiveness' may mean here). Thus, with various institutional settings and with varying visibility, empirical research has an important role in the didactics of mathematics. Because of the complexity of the field, direct cause-effect research (mimicking classical natural science research) was soon found difficult, if not impossible. Nevertheless, partly as a fallout from the need to design learning environments, empirical research in European didactics of mathematics developed a variety of questions, aims, topics and research methods such as statistical analysis with the help of tests and questionnaires, content analysis of curricula and textbooks, and classroom analysis with the help of video and observation sheets that was sometimes followed by transcript analysis (often 
with concepts from linguistics). More recently, triangulation and mixed methods complement the range of research methods used in empirical research in all four countries.

A major division in the plethora of empirical research is the difference between large-scale research and small and medium-sized case studies. The COACTIV study in Germany is a prototype of large-scale research. It was designed to investigate teacher competence as a key determinant of instructional quality in mathematics (for more details on this study, see Kunter et al., 2013). A contrasting example is Mithalal's case study on 3D geometry. Using Duval's déconstruction dimensionelle and the theory of didactical situations as the theoretical framework (see Sect. 1.3), the study took a qualitative approach to analysing students dealing with the reconstruction of a drawing showing a 3D configuration (for details see https://hal.archives-ouvertes. fr/tel-00590941).

Large-scale research can be further distinguished from medium- or small-scale research along the following lines: Large-scale studies tend to make differences within a representative sample an argument, while small- or medium-scale studies tend to make specialities of the 'case' an argument. In addition to this, empirical research can be distinguished along methodological lines: Quantitative studies tend to use sophisticated statistical techniques, while qualitative studies tend to use techniques from content analysis. In addition, there are, to an increasing proportion, mixed methods studies which use both qualitative and quantitative techniques.

If we look into the purposes of empirical research, we find commonalities and differences in these four countries. Prescriptive studies, which tend to show how things should be, are found in all countries, as are descriptive studies, which tend to give the best possible description and understanding of the domain under study while not being primarily interested in changing the domain. We find experimental studies on theories on the didactics of mathematics, which are undertaken to develop or elaborate a theory and put it to a test, in Italy, France and the Netherlands (less frequently in Germany), while illustrations of an existing theory (as a sort of 'existence proof') can be found in all four countries.

Another distinction is action research as opposed to fundamental research. Action research is deeply involved with the phenomena and persons under study and has the main aim of improving the actual teaching and learning. This is widespread in Italy and the Netherlands. In contrast to this, fundamental research tends to prioritise understanding of the phenomena under study and has the major aim of improving theoretical concepts: This type of research can be found in all four countries. An additional purpose of empirical research can be specific political interests (in contrast to the development of science or in addition to an interest in scientific progress and curriculum development). This type of research can be found particularly in Germany. 


\subsection{The Presented Cases}

In Chaps. 2-7, the four didactic traditions that were referred to in the preceding sections as well as two more traditions are presented in detail.

The first presented tradition in Chap. 2 is the French. First, the emergence and development of this tradition according to the four key features are described. In particular, the three main theoretical pillars of this tradition are discussed in detail, namely the theory of didactical situations, the theory of conceptual fields and the anthropological theory of the didactic. The French tradition is then illustrated through two case studies devoted to research carried out within this tradition on line symmetry and reflection and on algebra. In the following sections, the influence of the French tradition on the mathematics education community at large is shown through the contributions of four researchers from Germany, Italy, Mexico and Tunisia. The German view of the French didactic tradition is examined through a detailed look at didactic research on validation and proof. Interactions in didactics of mathematics between France and Italy are exemplified by means of collaborative projects such as SFIDA and the personal trajectory of an Italian researcher. Didactic connections between France and Latin America are illustrated by a case from Mexico, and the long-standing connections between France and (in particular Francophone) Africa by a case from Tunisia.

In Chap. 3, the Dutch didactic tradition is presented. In the first section, the development of this tradition since the beginning of the 19th century is described with reference to the four key features. The most important feature, characteristic of the Dutch tradition, is the emphasis on design activities, strongly influenced by the IOWO institute (which since 1991 has been called the Freudenthal Institute after its first director). The second section is devoted to Adri Treffers' ideas and conceptions for RME at the primary level, with an emphasis on pupils' own productions and constructions. The third section describes the contribution of another exponent of RME, Jan de Lange, and gives examples of the use of real-world contexts for introducing and developing mathematical concepts. The fourth section gives an illustration of how the principles of RME can guide the design of a new task, using the context of a car trip to Hamburg. The chapter finishes by letting voices from abroad speak about the influence of Dutch conceptions, especially RME, on mathematics education in other parts of the world: the US, Indonesia, England, South Africa and Belgium.

The Italian didactic tradition is the content of Chap. 4. After a short historic overview, some of the crucial features that shaped Italian didactics of mathematics are presented. It becomes clear how local conditions, especially the high degree of freedom left to the teacher, influenced the design and the implementation of didactic interventions. Afterwards, the long-standing fruitful collaboration between French and Italian researchers is described and illustrated both by joint seminars and by concrete Ph.D. cases. In the final section, the collaboration between Italian and Chinese mathematics educators gives rise to a view on the Italian tradition, both culturally and institutionally, from an East Asian perspective. 
Chapter 5 contains a summary of the German-language didactic tradition. The chapter starts with a historical sketch of German-speaking didactics of mathematics, starting with the 1960s. Section 5.2 gives an overview of the present situation of didactics of mathematics in the 21 st century, distinguishing between three major strands: one mainly oriented towards the analysis of subject matter and the design of learning environments, one emphasising small-scale classroom studies, and one following a large-scale paradigm for analysing the learning and teaching of mathematics and the professional competencies of teachers. The last two strands are illustrated by two examples of research studies. Section 5.3 looks briefly into the future of Germanlanguage didactics of mathematics. Section 5.4 introduces perspectives from outside the German-language community. Researchers from the Nordic countries of Norway and Sweden, from Poland and from the Czech Republic present and comment on interactions concerning research in didactics of mathematics in their own countries and the German-speaking countries.

Chapter 6 presents a survey of the development of didactics of mathematics as a research domain in the Scandinavian countries of Denmark, Norway and Sweden. After an introduction, Sect. 6.2 presents a historical overview about the situation in these three countries, starting in the 1960s. In Sect. 6.3, some important trends that have been of particular importance in each of these countries are described. The following three sections take a detailed look into the situation in each of the three countries, emphasising special features of research in mathematics education in these countries such as work on mathematical competencies in Denmark, the social-cultural tradition in Norway and studies with a focus on low achievers in Sweden. Section 6.7 reports on common activities and collaborative projects, such as the NORMA conferences and the journal NOMAD, between these three countries and between these countries and Finland, Iceland and the Baltic countries.

The Czech and Slovak didactic tradition is discussed Chap. 7, presenting the emergence of research in didactics of mathematics in the former Czechoslovakia and the developments after the revolution in 1989. Section 7.2 shows that before 1989, Czechoslovak research developed relatively independently from other parts of Europe, yet its character shows similar key features as identified in Western European countries. In Sect. 7.3, research after 1989 is presented. The research fields are divided into four major strands: development of theories (such as the theory of generic models), knowledge and education of mathematics teachers, classroom research (e.g., related to scheme-based education at the primary level) and pupils' reasoning in mathematics. Each strand is illustrated by relevant work by Czech and Slovak researchers, with a focus on empirical research. The chapter is rounded off by naming some perspectives and challenges for didactics of mathematics in the Czech Republic and Slovakia. 


\section{References}

Arzarello, F., \& Bartolini Bussi, M. G. (1998). Italian trends of research in mathematics education: A national case study in the international perspective. In J. Kilpatrick \& A. Sierpinska (Eds.), Mathematics education as a research domain: A search for identity (pp. 243-262). Dordrecht: Kluwer.

Bikner-Ahsbahs, A., \& Prediger, S. (Eds.). (2014). Networking of theories as a research practice in mathematics education. Heidelberg: Springer.

Blum, W., Artigue, M., Mariotti, M. A., Sträßer, R., \& Van den Heuvel-Panhuizen, M. (2017). European didactic traditions in mathematics: Aspects and examples from four selected cases. In G. Kaiser (Ed.), Proceedings of the 13th International Congress on Mathematical Education-ICME-13 (pp. 291-304). Cham: Springer.

Brousseau, G. (1997). Theory of didactical situations in mathematics. Dordrecht: Kluwer.

Chevallard, Y., \& Sensevy, G. (2014). Anthropological approaches in mathematics education, French perspectives. In S. Lerman (Ed.), Encyclopedia of mathematics education (pp. 38-43). New York: Springer.

Freudenthal, H. (1983). Didactical phenomenology of mathematical structures. Dordrecht: Kluwer. Griesel, H. (1974). Überlegungen zur Didaktik der Mathematik als Wissenschaft. Zentralblatt für Didaktik der Mathematik, 6(3), 115-119.

Jahnke, H.-N., Biehler, R., Bikner-Ahsbahs, A., Gellert, U., Greefrath, G., Hefendehl-Hebeker, L., ... Vorhölter, K. (2017). German-speaking traditions in mathematics education research. In G. Kaiser (Ed.), Proceedings of the 13th International Congress on Mathematical Education-ICME-13 (pp. 305-319). Cham: Springer.

Kunter, M., Baumert, J., Blum, W., Klusmann, U., Krauss, S., \& Neubrand, M. (Eds.). (2013). Cognitive activation in the mathematics classroom and professional competence of teachers-Results from the COACTIV project. New York: Springer.

Tobies, R. (1981). Felix Klein. Leipzig: Teubner.

Van den Heuvel-Panhuizen, M., \& Drijvers, P. (2014). Realistic mathematics education. In S. Lerman (Ed.), Encyclopedia of mathematics education (pp. 521-525). Dordrecht: Springer.

Vergnaud, G. (1991). La théorie des champs conceptuels [The theory of conceptual fields]. Recherches en Didactique des Mathématiques, 10(2-3), 133-170.

Winter, H. (1975). Allgemeine Lernziele für den Mathematikunterricht. Zentralblatt für Didaktik der Mathematik, 7(3), 106-116.

Wittmann, E. (1974). Didaktik der Mathematik als Ingenieurwissenschaft. Zentralblatt für Didaktik der Mathematik, 6(3), 119-121.

Open Access This chapter is distributed under the terms of the Creative Commons Attribution 4.0 International License (http://creativecommons.org/licenses/by/4.0/), which permits use, duplication, adaptation, distribution and reproduction in any medium or format, as long as you give appropriate credit to the original author(s) and the source, a link is provided to the Creative Commons license and any changes made are indicated.

The images or other third party material in this chapter are included in the work's Creative Commons license, unless indicated otherwise in the credit line; if such material is not included in the work's Creative Commons license and the respective action is not permitted by statutory regulation, users will need to obtain permission from the license holder to duplicate, adapt or reproduce the material.

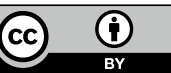

